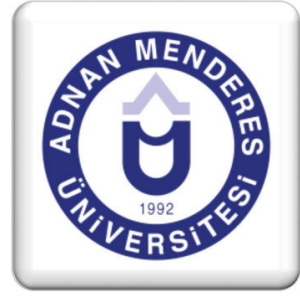

\section{Patent Verileri ve Teknolojik Sinıflama Sistemleri}

\section{Patent Data and Technological Concordance Systems}

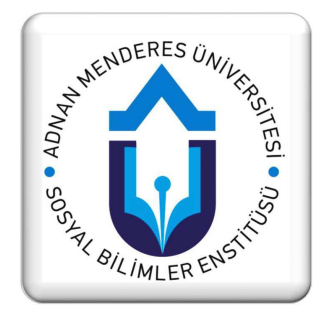

Kurtuluş

Bozkurt*

*Yrd. Doç. Dr.

Adnan Menderes

Üniversitesi

Söke İşletme Fakültesi

Bankacllık ve Finans

Bölümü

Anahtar Kelimeler: Patent, IPC, MERIT, YTC, OTC 


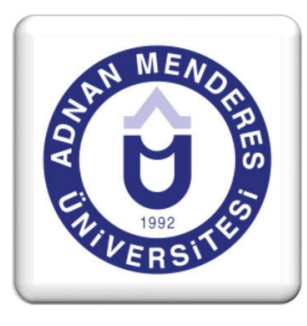

\section{Patent Verileri ve Teknolojik Sinıflama Sistemleri}

\section{Patent Data and Technological Concordance Systems}

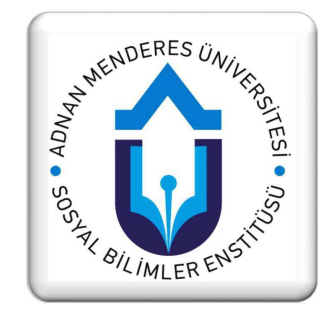

\section{Abstract}

Adventure that brought today's world of globalization and information technology-based competitive strategy-oriented, conceptual sense, technological activities and / or economic sense, requires the identification of information which serve as the data can be analyzed. Because the sine qua non of the concept of economic growth by one of the dynamic elements of knowledge-based activities along with increased national and / or economic activities and trade in the international arena has contributed to the development is very important. In this context, economic and technological development will enable the analysis done in the best way to describe the information indicative of data quality that makes the necessary arrangements to gain a highly complex and technical field. One of the most significant gains in this area of Intellectual and Industrial Property rights and technological activities constitute one of the most important elements of the classification of the activities of the patent is. At this point, data format conversion of the activities of this work with patents and patent-related technical regulations regarding the use of a number of data points referring to the basic objective of providing an important contribution to the literature on the subject is national.

Key Words: Patent, IPC, MERIT, YTC, OTC 


\section{Giriş}

Patent verileri hemen hemen birçok ülke için meta veri dosyaları olarak düzenlenmekle birlikte ekonomik analiz açısından söz konusu düzenlenmiş patent veri dosyaları çokta anlamlı olmamaktadır. Bu noktada söz konusu patent dosyalarının teknolojik ve sektörel sınıflaması oldukça önemli bir çalışma alanını oluşturmaktadır. Patent verileri ulusal patent ofisleri tarafından Uluslararası Patent Sınıflaması (IPC) sistemi temelinde teknolojik içeriklerine göre sınıflandırılarak kayıt altına alınmaktadır. Ancak patentlerin ekonomik etkilerinin analizi yapılırken tek başına IPC sınıflamasının sağlamış olduğu bilgiler anlamlı olmayabilmektedir. Bu noktada söz konusu patent verilerinin sektörel sınıflamalarının da yapılması ekonomik analiz açısından son derece önemlidir.

Bu noktada literatürde patent verilerinin sektörel sınıflamasını yapan üç temel sektörel sınıflama sistemi bulunmaktadır. Bunlar sirasıyla MERIT Sinıflama Sistemi, YTC Sinıflama Sistemi ve OECD (OTC) Sınıflama Sistemleridir. Temelde söz konusu sektörel sınıflama sistemleri IPC tabanlı patent verilerini kullanarak sektörel bir ayrıma tabi tutmaktadır. Bu ayrım özellikle ekonomistler açısından patent faaliyetlerinin sektörel dağılımlarını ve sektörler arası eğilimlerini analiz etmek, sektörel anlamda teknolojik yenilik faaliyetlerinin verimliliğini (Ar\&Ge birimi başına düşen patent tescil sayısı v.b.) ölçmek ve bu noktada politika yapıcılar açısından desteklenecek sektörlerin tespit edilmesi noktasında son derece önemlidir. Bu bağlamda bu çalışmada öncelikle bilimsel ve teknolojik faaliyetlerin göstergesi olan patentlerin kullanılması ile ilgili avantaj ve dezavantajların tespiti yapılacak, ikinci olarak patent sınıflama sistemleri hakkında teknik düzeyde bilgiler verilecektir.

\section{Teknolojik Gelişmelerin Kaynağı Olarak Bilimsel ve Teknolojik Faaliyetler}

Bilimsel ve Teknolojik Faaliyet (BTF) kavramı ilk olarak UNESCO tarafından geliştirilmiştir (OECD, 1980: 2). UNESCO' ya göre; bilimsel ve teknolojik faaliyetler, bilim ve teknoloji alanında bilimsel bilginin üretilmesi, geliştirilmesi, yayılması ve uygulanması ile ilgili; araştırma ve geliştirme (A\&G), bilimsel ve teknik eğitim ile bilimsel ve teknik hizmet faaliyetlerini kapsamaktadır (UNESCO, 1978: 1).

Bilimsel ve teknik eğitim; üniversite dışı uzmanlaşmış yüksek eğitimi, lisans eğitimini, lisansüstü ve doktora eğitimi ile bilim adamları ve mühendisler için örgütlenmiş her türlü teknik eğitim faaliyetlerini kapsamaktadır (UNESCO, 1978: 1). Bilimsel ve teknik hizmetler ise; araştırma ve geliştirme ile ilgili, bilimsel ve teknik bilginin üretilmesi, yayılması ve uygulanmasına katkıda bulunan faaliyetlerdir (OECD, 1980: 2). Bu faaliyetler ise; bilimsel ve teknik insan gücü, kaynak tarama birimleri, patent birimleri tarafından yapılan toplama, kodlama, kayıt, sınıflandırma, yayma, çevirme, analiz ve değerlendirme çalışmaları, bilimsel ve teknik bilgi yayımı ve danışma hizmet birimleri ile bilimsel amaçlı konferans ve toplantıları kapsamaktadır (OECD, 1980: 2-4).

Bilimsel ve teknolojik faaliyetler, yenilik (inovasyon) sürecinin beraberinde getirmiş olduğu; verimlilik ve rekabet gücü artışlarının ekonomik analizi için önemli bir unsuru oluşturmaktadır. Bilim ve teknoloji faaliyetleri, bir ülkenin teknoloji kapasitesini ve ekonomik kalkınmasının seyrini belirler. Dolayısıyla; bilim ve teknoloji faaliyetleri ile ekonomik değişkenler arasındaki ilişkinin anlaşılabilmesi ve iktisadi anlamda bu ilişkinin modellendirilebilmesi için, bilim ve teknoloji faaliyetlerini temsil edebilecek göstergelerin bulunması gerekmektedir. Bu noktada; OECD bilim ve teknoloji faaliyetlerine ait göstergeleri, bilim ve teknoloji faaliyeti girdileri (BTFG) ile bilim ve teknoloji faaliyeti çıktıları (BTFÇ) olarak ikiye ayırmaktadır (OECD, 1994: 3-4). BTFG; A\&G personelini, A\&G harcamaları ve teknik danışmanlık hizmetlerini, knowhow harcamalarını ve $A \& G$ yoğun donanım yatırımlarını kapsarken, BTFÇ ise; bilimsel yayınları ve patent başvurularını kapsamaktadır. Diğer taraftan, tekno-metrik standartlar, inovasyon testleri, A\&G yoğun malların ticareti, üretim hacmi ve teknoloji değerlendirmeleri gibi göstergelerde bilim ve teknoloji faaliyetlerine ait göstergeler gibi algılanabilmektedir.

Literatürde, genel olarak, en çok BTFG olarak A\&G harcamaları ve BTFÇ olarak da doğrudan inovasyon harcamaları ile patentler kullanılmaktadır. Ancak, her bir göstergeyi kullanmanın avantajları ve 
dezavantajları vardır. Bu noktada; A\&G yatırımları veya A\&G harcamaları BTF' yi temsil eden bir değişken olarak kullanılabilir. Fakat A\&G verilerini kullanmak bazı problemleri de beraberinde getirmektedir. İlk olarak; dünya genelinde, tüm ülkelere ait $A \& G$ verileri ya zaman serisi olarak hiç bulunmamakta ya da kısa bir zaman süreci için bulunabilmektedir. Bu sorun özellikle Türkiye gibi gelişmekte olan ülkeler açısından daha da büyümektedir. İkinci olarak; A\&G faaliyetleri iç içe geçmiş endüstriyel faaliyetleri kapsamaktadır ve bu durum $A \& G$ faaliyetlerinin sektörel sınıflamasında bazı sorunları beraberinde getirmektedir. A\&G verilerinde, $A \& G$ faaliyetlerinin ve yeniliklerin yapıldığ bulunmamaktadır.

Son olarak; A\&G verilerinin tasnifindeki ve sektörel sınıflamasındaki sorunlar aşılsa bile, A\&G faaliyetleri buluşla, inovasyon veya herhangi bir olumlu gelişme ile sonuçlanmayabilir. Dolayısıyla; herhangi bir buluş, inovasyon veya ürün ile sonuçlanmayan $A \& G$ faaliyetlerinin, hacmi ne kadar büyük olursa olsun, ekonomik analiz açısından hiçbir değeri olmamaktadır. Diğer taraftan; A\&G verileri, teknoloji alanları ile $A \& G$ faaliyetinde bulunan firmalar hakkında bize detaylı bilgiler vermemektedir (EIMS, 1996).

En güvenilir olarak kabul edilen BTFÇ göstergelerinden biri, doğrudan buluş ve inovasyonların tespit edilmesidir. Ancak, bunların tespit edilmesi tek tek firmalar ile görüşülmesini gerekli kılmaktadır. Bu ise sadece zaman açısından değil, maddi açıdan da maliyetlidir ve bazı küçük yenilik faaliyetlerinin anketlerle tespit edilmesi zor olabilmektedir. Tüm bu anlatılanlar dâhilinde; literatürde, herkes tarafından güvenilirliği kabul edilen patent verilerinin, BTF' yi temsil eden bir gösterge olarak kullanması kaçınılmaz olmaktadır (Johnson ve Evenson, 1997: 180).

\subsection{Bilimsel ve Teknolojik Faaliyetlerin Göstergesi Olarak Patentler}

Patentler, teknolojik gelişmenin seyrini belirleyen bilimsel ve teknolojik faaliyetlerin bir çıktısı olarak algılanabileceği gibi, aynı zamanda, patentleri $A \& G$ faaliyetlerinin nihai bir ürünü (çıktısı) gibi algılamak da mümkündür. Dolayısıyla, patent verileri A\&G harcamaları ile doğrudan ilişkili olmaktadır. Diğer bir ifade ile patent verileri ile $A \& G$ faaliyeti arasında pozitif yönlü ve güçlü bir ilişki vardır. Zira teknolojik yenilik amacıyla başlatılan $A \& G$ faaliyetlerinin başarısı başlangıçta bilinemeyeceğinden, pratikte bu faaliyetlerden bazıları başarısız olabilmekte ve ancak başarılı olan A\&G faaliyetleri için patent alma şansı doğmaktadır. Dolayısıyla; A\&G harcamaları ile patent sayısı arasında birebir bir ilişkiden ziyade güçlü bir pozitif ilişkinin varlığından bahsetmek daha anlamlıdır. Bu pozitif etkiden dolayı, A\&G verilerinin bulunmadığı veya $A \& G$ verilerine ulaşılamadığı durumda patent verileri A\&G verileri yerine kullanılabilmektedir (Griliches, 1990: 1665).

Patent verilerinin kullanımında bazı problemler olsa da, inovasyon veya $A \& G$ faaliyetinin bir temsilcisi gibi kullanılabilen patent verileri, bize önemli bilgiler vermektedir. Ancak bu problemleri de göz ardı etmemek gerekir. Dolayısıyla, söz konusu bu problemlere değinmek yerinde olacaktır.

\subsection{Patent Verisi Kullanımındaki Problemler}

Griliches (1990: 1665), genelde, patent verilerini kullanmanın iki temel problemi beraberinde getirdiğini vurgulamaktadır. Bunlardan ilki; patentlerin sınıflandırılması ile ilgili iken, ikincisi; patentlerin içerdiği değişken teknolojilerle ilgilidir. Sınıflama problemi; her bir buluş veya patentin, bir ürün veya sanayi grubu ile ilişkilendirilerek sınıflandırılması ile alakalıdır. Bu noktada, söz konusu patente veya buluşa ait teknoloji alanı ile ilgili, eğitimli ve bilgili elemanların varlığı önem kazanmaktadır. Dolayısıyla söz konusu teknoloji alanındaki uzman eksikliği, patentlenecek teknoloji aktivitesinin sınıflandırılamamasına yol açacak, ayrıca yeni ürün ve süreç gelişimleri ile bu sorun daha da artacaktır (Griliches, 1990: 1665). Diğer bir ifade ile yeni teknolojiler ortaya konurken, bu yeni teknolojilerin yeni patent sınıfları içinde sınıflandırılması zorlaşmakta ve bu gibi durumlarda yeni teknolojilere ait patent verileri, ham veriler olarak kalmaktadır (OECD, 1994: 5). 
İkinci büyük problem, patentlerin içerdiği değişik teknolojilerle ilgilidir. Patentlenen bazı buluş ve yenilikler ekonomik ve teknolojik anlamda günün koşullarına göre çok büyük değişiklikler yaratırken, bazı patentler ise sadece var olan teknolojilere çok az ekonomik değer kazandırmaktadır. Diğer bir deyişle, bazı patentler insan hayatının kalitesinde bir ilerleme sağlarken, bazılarında böyle bir katkı yoktur. Bu iki tür patentleri birbirinden ayırmak çok önemli olsa da maalesef bunu yapmak için elimizde kolay ve uygulanabilir herhangi bir yöntem bulunmamaktadır.

Sınıflandırma ve temsili değişik teknoloji sorununa ek olarak, ayrıca, patent verilerini kullanırken bazı ampirik sorunlarda çıkabilmektedir. Griliches (1990: 1670) bu ampirik sorunları üç temel noktada toplamıştır. Bunlar:

i.) Tüm buluş veya icatlar sadece patent koruması ile korunmamaktadır. Buluş veya icatlar, patent dışında; gizlilik, hızlı yayılmacı buluş ve düşük fiyat uygulaması gibi yöntemlerle de korunabilir. Firmalar rekabeti azaltmak için, yapmış oldukları icatları gizli tutabilirler, piyasaya ürünlerini çok hızlı bir şekilde sürebilirler veya düşük fiyat politikası izleyebilirler. Dolayısıyla tüm bu uygulamalarda patent korumasının yerini tutabilmektedir (OECD, 1994: 10).

ii.) Ayrıca bazı buluşlar patentlenebilir nitelikte olmayabilir. Örneğin; bilimsel teoriler, matematiksel yöntemler, doğal kaynakların keşfi, ticari yöntemler veya tıbbi tedavi yöntemleri patentlenemeyecek buluşlardır. Ayrıca, kamu düzenine ve ahlaka aykırı buluşlarda patentlenememektedir.

iii.) Patentli buluşlar kendi arasında kalite açısından farklılıklar gösterir. Bazı buluşlar üretken olup birçok yeni buluşun ortaya çıkmasına aracı olurken, bazı buluşlar sadece mevcut buluşlara küçük katkılar sağlayan nitelikte buluşlar olabilir. Diğer bir ifade ile patentli buluşlar kendi arasında bile nitelik açısından farklılıklar göstermekte olup homojen değillerdir.

Diğer taraftan bu ampirik sorunlara ilaveten, patentleme eğiliminin şirketten şirkete, sektörden sektöre ve ülkeden ülkeye farklılıklar göstermesinden kaynaklanan sorunlar da vardır. Dolayısıyla, firmalar, sektörler ve ülkeler arasında patentleme eğiliminin farklılıklar göstermesi, firmalar, sektörler ve ülkeler arası karşılaştırmalı analiz yapılmasını zorlaştırmaktadır.

Her ülkede patentlerle ilgili farklı yasal ve kurumsal düzenlemeler olabilir. Dolayısıyla bu yasal ve kurumsal farklılıklar, ülkeler ve coğrafi bölgeler arasında benzer olmayan patentleme davranışlarına yol açabilir. Ayrıca, ülkelerin, firmaların veya sektörlerin patent faaliyetleri dönemler arasında bile farklılıklar gösterebildiği gibi, firmaların yerli veya yabancı patent koruması talepleri de ülkeden ülkeye farklılıklar gösterebilmektedir. Dolayısıyla, bu farklılıklar, firmaların patentleme stratejileri dâhilinde ülkeler arası farklılıklara yol açabilmektedir.

Yukarıda değinildiği üzere, patentleme eğilimleri sektörden sektöre de değişmektedir. Örneğin; elektronik ve hava yolu gibi sektörlerdeki patentleme eğilimi, kimya ve mühendislik sektörlerindeki patentleme eğiliminden oransal olarak daha azdır (OECD, 1994: 10). Dolayısıyla sektörler arasındaki bu farklılıklar yine sektörler arası karşılaştırmalı analiz yapmamızı zorlaştırmaktadır. Yine benzer şekilde, firmalar düzeyinde de patentleme eğiliminde farklılıklar söz konusu olmaktadır. Firmaların patent eğilimleri, genişliklerine, faaliyette bulundukları teknoloji alanlarına ve yapmış oldukları buluşların karakteristik özelliklerine göre değişmektedir (OECD, 1994: 10). Genel olarak, firmalar ürün yeniliklerinde patent korumasını tercih ederken, süreç yeniliklerinde patent dışı koruma araçlarını tercih etmektedirler (OECD, 1994: 10).

Ülkeler arasındaki patentleme eğilimi farklılıkları ise, daha çok gelişmişlik farklılıklarından kaynaklanmaktadır ve patent verilerinin kullanılmasına yönelik olarak ortaya çıkan sorunlar daha çok gelişmekte olan ülkeler için geçerli olmaktadır. Gelişmekte olan ülkelerde, bilimsel ve teknolojik faaliyetler, gelişmiş ülkelere kıyasla daha azdır ve gelişmekte olan ülkeler, genel olarak patentleme aktivitesinden ziyade yabancı teknolojiyi adapte ederek kullanmayı tercih ederler. Dolayısıyla gelişmekte olan ülkeler, patentlere gerek kalmaksızın bu tür teknolojik bilgilere rahatlıkla sahip olabildikleri için, patentleme faaliyeti yerine, daha çok, teknolojinin nasıl adapte edileceği ve kullanılacağı ile ilgilenirler. Dolayısıyla 
gelişmekte olan ülkelerdeki yerli patent verileri, söz konusu gelişmekte olan ülkelerin teknoloji faaliyetlerini tam anlamıyla yansıtamayabilir (Albuquerque, 2000: 1047). Ayrıca, herhangi bir teknolojik değişme durumunda, yerli patent istatistikleri, sermaye malı ithalatları ve teknoloji lisansı vb. teknoloji transferi mekanizmaları kadar, söz konusu teknolojik değişmeyi göstermek açısından başarılı olamayabilir (Albuquerque, 2000: 1047).

Patent verilerini kullanmanın yol açtığı bu sorunlara karşılık, patent verilerini kullanmanın birçok avantajı da bulunmaktadır. Dolayısıyla bu avantajlara değinmek yerinde olacaktır.

\subsection{Patent Verilerini Kullanmanın Avantajları}

Her ne kadar ülkelerin, sektörlerin ve firmaların patentleme eğilimlerinde farklılıklar gözlemlense ve bu problem gelişmekte olan ülkelerde daha da belirgin olarak ortaya çıksa da patent verileri BTF'nin en önemli göstergelerinden birisidir (Schmookler, 1966). Çünkü patent verilerindeki bilgiler detaylandırılmış bilgilerdir ve bu bilgilere bilgisayar ortamında çok rahat ulaşılabilmektedir (Patel, 1995: 141). Ayrıca Albuquerque (2000: 1047), gelişmekte olan ülkelerdeki yerli patentlerin, Amerika Patent ve Marka Ofisindeki patentlere kıyasla, teknoloji faaliyetlerini daha iyi temsil ettiğini vurgulamaktadır.

Patent verisi, A\&G çıktısı ile buluş ve inovasyon aktiviteleri için iyi bir temsilcidir ve bir ülke veya sektörün teknoloji düzeyi hakkında detaylı ve yeterli bilgiye sahip olunamadığı durumlarda, patentler bu bilgileri bize sağlamaktadır (Griliches, 1990: 1661). Dolayısıyla; A\& G verileri gibi, çoğu gelişmekte olan ülkeler ve hatta gelişmiş ülkeler için, bilimsel ve teknolojik faaliyet göstergelerinin eksikliği patent verilerinin kullanılmasını gerektirmektedir. Ayrıca her düzeyde detaylı bilgi sağlayan patent verileri, diğer göstergelerden farklı olarak, ülkelerin, sektörlerin veya firmaların ekonomik ve teknolojik gelişmelerinin seyrini de analiz etmemizi sağlar (Griliches, 1990: 1661). Diğer taraftan patent verileri bilimsel ve teknolojik faaliyet çıktı göstergesi olarak kullanılabildiği gibi, bazı durumlarda, bilimsel ve teknolojik faaliyet girdisi olarak kullanılabilmektedir.

Patent verileri, dünya genelinde, patent ofisleri tarafından bilgisayar ortamında belirli bir sistematik içerisinde verileştirildiği için; firma, sektör veya ülke düzeyinde teknolojik gelişmenin seyrinin analiz edilmesinde güvenilirlik arz etmektedir. Çünkü bu veriler bir zaman serisi olarak sunulmaktadırlar. Dolayısıyla; patent verileri aracılığı ile ülkelerin buluş çıktı düzeyi ve rekabet kapasiteleri arasındaki ilişkinin analiz edilmesi mümkün olmaktadır (Griliches, 1990: 1661). Diğer taraftan; bir ülkedeki yabancı patent başvurularının ve teknolojik faaliyetlerin dağılımını görmemizi de sağlamakta ve yabancıların söz konusu ülkede hangi teknolojik alanlara yöneldiği hakkında bilgi sağlamaktadır (OECD, 1994: 5).

Firma düzeyindeki patent verileri, firmaların hangi alanlarda buluş faaliyetlerinde bulundukları, niçin patent başvurusu yaptıkları gibi firma stratejileri hakkında bilgi vermektedir. Yine firmaların üretimde bulundukları teknolojik alanlar veya sektörler ile bu alanlarda gerçekleştirmiş oldukları ekonomik ve ticari faaliyetlere yönelik stratejileri hakkında da bilgi verir (OECD, 1994: 5). Diğer taraftan; firmaların patent verileri inovasyonların firma genişliklerine göre dağılımını ve piyasa içerisindeki yoğunlaşma derecelerini gösterir (OECD, 1994: 5).

Patent verileri, ekonomik analiz yapmamızı kolaylaştıran, patentin mucidi, söz konusu patentin teknoloji alanı, buluşun içeriği v.b. gibi birçok toplulaştırılmış detaylı bilgiye ve sınıflandırmalara sahiptir. Dolayısıyla, patent verilerinin beraberinde getirmiş olduğu söz konusu detaylı bilgi, teknolojinin yayılmasını sağlamakta ve hatta kopyalanmasına da yol açmaktadır. Böylece söz konusu bu detaylı bilgi; ülkeler, firmalar ve sektörler arasındaki dışsallıkların analiz edilmesini mümkün hale getirmekte, ekonomideki veya firmalardaki $A \& G$ faaliyetlerinin sağladığı dışsal etkileri tanımlamamızı sağlamaktadır.

Diğer taraftan; patent dosyaları, patent başvurularının teknolojik alanlara ayrıştırılmasını sağlayan araştırma ve inceleme raporlarını içerdiği için; patentlerin teknolojik alanlarının endüstriyel sınıflamasına çevrilmesi ile buluşu üreten ve kullanan sektörleri analiz etmemizi sağlar. Buluşu kullanan ve üreten sektörlerin ayrımı; ülkeler, firmalar ve sektörler arası bağların araştırılmasını mümkün kılar. 
Patent dosyaları, daha önceki patentlere ve diğer bilgilere olan atıfları da içermektedir. Bu bilgiler özellikle var olan ve yeni bilgi stokları arasındaki ilişkinin belirlenmesinde önemlidir. Bu bağların kurulması, bilgi dışsallıklarının firmalar, endüstriler ve ülkeler arasındaki yayılımın belirlenmesinde önemlidir.

Patent dosyalarında var olan detaylı buluş tanımlamaları, buluş faaliyetlerinin devam etmesinde önemli bir rol üstlenmekte ve yeni düşüncelerin ortaya çıkmasını sağlamaktadır. Bu da söz konusu patent dosyasındaki buluş tanımlamasının dilinin anlaşılır olması ve bu tanımlamaların yaratıcı yeni düşünce veya buluşları adapte edebilecek kapasitede olması ile mümkündür. Dolayısıyla; bu tür bilgilerin açık olması ile patentler yeni yaratıcı düşüncelerin ve tekrarlanan buluşların oluşmasına imkân sağlayacak pozitif dışsallıklar yaratacaktır (Mazzoleni \& Nelson, 1998: 273).

Ayrıca; patent dosyaları, patentin mucidi, mucidin adresi ile milliyeti ve patentin kullanım hakkının kime ait olduğu ile ilgili detaylı bilgiler verir. Çoğu zaman mucit ile patent hakkını kullanan organizasyon' un ismi veya isimleri farklı olabilir. Örneğin; firmalar işçisinin buluşunu kullanabilir veya buluşun kullanım hakkı firmaya lisanslama yolu ile verilebilir. Dolayısıyla; patent dosyalarında iki adres mevcuttur. Bunlardan ilki, buluşa ait mucidin adresi, ikincisi de patent hakkını kullanan firma veya şâhısa ait adrestir.

Diğer taraftan; patent hakkını kullanan çokuluslu bir firmada olabilir. Böyle bir durumda, patentte ait buluşun mucidinin adresi ve milliyeti ile şubenin adresi ve milliyeti de patent dosyalarında içerilmektedir. Dolayısıyla; patent dosyaları, deniz aşırı şubeleri bulunan çokuluslu firmalar açısından, söz konusu çokuluslu firmalar ile deniz aşırı şubeleri arasındaki ilişkiler hakkında da bilgiler verir.

Patent dosyalarındaki bu adres bilgileri dünya genelinde veya herhangi bir bölge ya da ülke genelinde patentlerin dağılımını bize gösterir. Dolayısıyla patent aktivitelerinin coğrafi dağılımı, teknoloji aktivitelerinde görülen bölgesel farklılıkları analiz etmemizi sağlar (Guerrero \& Sero, 1997: 381). Patent dosyaları, ayrıca, söz konusu ülkedeki veya bölgedeki patent koruması statüsü ve bu ülkeler veya bölgelerdeki firmaların patent koruması stratejileri hakkında bilgiler verir. Diğer taraftan; patent koruma süreleri, patent ölüm istatistikleri ve patent yenileme oranı, bize, söz konusu ülkede veya bölgede patentlerin önemi hakkında bilgiler verir (Griliches, 1990: 1661).

Diğer taraftan; patent başvuruları birden fazla ülke için yapılabilmektedir. Bu durumlarda, patent korumasını talep edenler açısından, patent korumalarının varlığı birden fazla ülke için araştırılır. Dolayısıyla yine belirtilen ülkeler hakkındaki bilgiler patent dosyalarında içerlenir. Böylece, bu bilgiler aracılığı ile söz konusu ülkelerdeki buluş ve inovasyon piyasaları hakkında veya firmaların üretim planları hakkında bilgi sahibi olabiliriz.

Özetle; detaylı bilgiler içeren patent dosyaları, bir ülkenin, firmanın veya sektörün teknolojik gücünü değerlendirebilmemizi, karşılıklı ülkelerin patentleme faaliyetlerini ve rekabet güçlerini analiz edebilmemizi, söz konusu ülkelerin sektörel uzmanlaşmasını ve teknolojik ürün dönemlerini araştırabilmemizi mümkün kılmaktadır.

\subsection{Patent Verilerinin Kullanımı}

Bilimsel ve teknolojik faaliyetlerin bir göstergesi olarak kullanılan patent verilerinin kullanımında, birkaç çeşit patent ölçüsü kullanılır. Bunlar; basit patent sayımı, patent referansları, uzmanlaşma endeksleri, bilim ile ilişkileri ve firmaların pozisyonlarını tespit eden göstergelerdir. Söz konusu bu göstergeler, firma, sektör veya ülkelerin, toplulaştırılarak farklı düzeylerde analiz edilmesine olanak sağlamaktadır (OECD, 1994: 26).

Patente dayalı ölçüler, teknoloji- bilim ilişkisini tespit eden göstergeler, ülke, sektör veya firma düzeyinde toplulaştırılmış tüm ekonomik performans göstergeleri ve $A \& G$ yatırımlarının etkinliği göstergeleri gibi kullanılabilir. Dolayısıyla, patent göstergelerin bu şekildeki kullanımlarına kısaca değinmek yerinde olacaktır:

i.) Teknoloji bağlantılı gösterge olarak kullanımı; 
Patentler, sektörler arası teknolojik bağımlılığın bir göstergesi olarak kullanılabilir. Bu amaçla, patent referansları basit patent sayımlarına ilaveten kullanılabilir. Bu durumda; daha eski patentlere ait patent referansları ve patent sınıflamaları, sektörler arası dışsallıkları ve teknoloji bağlantılarını göstermek için kullanılabilir. Patent ofislerindeki araştırmacılar ile mucitlerin referans aldığı bu patentler, referans patentler olarak tanımlanır. Ayrıca, patent referansları sektörlerin önemlilik derecesini analiz etmemizi sağlar. Bir patente ne kadar referans verildiği ise o patentin içerdiği yenilik de o kadar önemli görülür. Böylece, bir sektörün diğer sektörler için olan önemi de ortaya konmuş olur (OECD, 1994: 26).

Ayrıca, patentler, bilimsel ve teknolojik faaliyet göstergesi olarak, sektörel düzeyde buluşların girdi- çıtı analizinde kullanılabilir. Bu durumda, patentlerin sektörel olarak sınıflandırılması gerekmektedir. Sektörel sınıflamayla, buluş ve/ veya yeniliği üreten sektörler ve bunları kullanan sektörler arasındaki ilişki kurularak, sektörler arasındaki teknolojik bağımlılık ortaya konur (OECD, 1994: 26).

ii.) Bilimsel ve teknolojik bağlantılı gösterge olarak kullanımı;

Araştırmacılar ve mucitler tarafından atıfta bulunulan bilimsel yazılar, bilimsel ve teknolojik bağlantılı göstergeleri oluşturmaktadır (OECD, 1994: 26).

iii.) $A \& G$ göstergelerinin etkinliğinin ölçümü için kullanımı;

$A \& G$ faaliyetlerinin ekonomik etkinliğinin ölçümünde, $A \& G$ faaliyetinin bir çıktısı olarak patent göstergeleri kullanılmaktadır. A\&G yatırımları ve $A \& G$ çıktısının karşılaştırılması ile A\&G etkinliği ölçülebilmektedir.

iv.) Ekonomik performans göstergesi olarak kullanımı;

Patent verileri, farklı düzeylerde, ekonomik performans göstergesi olarak kullanılabilir. Ülke düzeyindeki patent verileri, söz konusu ülkenin rekabet ölçüsü gibi kullanılabilir (OECD, 1994: 28). Ayrıca, patent verileri, üretim performansının ölçümünde, üretim sürecinde kullanılan teknoloji düzeyinin bir göstergesi gibi kullanılabilir. Basit patent sayımları ve firma veya sektör düzeyinde toplulaştırılmış tüm düzeylerdeki teknolojik çıktı göstergeleri, bir ülkenin rekabet göstergesi olarak kullanılabilir.

Patentler, bir ülkenin teknolojik gücünü, hangi sektörde veya sektörlerde uzmanlaştığını ve sektörler arası uzmanlaşmadaki farklılıkları göstermesi açısından önemlidir. Bunun için genellikle teknolojik avantaj veya uzmanlaşma endeksi kullanılmaktadır (bkz. OECD, 1994; Cantwell, 1995; Archibugi \& Michie, 1995; Patel \& Pavitt, 1995; Mancusi, 2000). Bu göstergeler, ülkelerin uzmanlaşma trendini ve göreceli teknolojik gücünü gösterir. Bu noktada, bir ülkenin herhangi bir teknolojideki gücünü veya zayıflığını " Açıklanmış Teknolojik Avantaj" (RTA) indeksi gösterir.

Son olarak; firma düzeyindeki analizlerde, patent sayımları, referansları ve uzmanlaşma endeksleri, patent üretiminde bulunan firmaların endüstriyel stratejilerinin ölçümü için kullanılabilir. Bu uzmanlaşma göstergeleri ile firmaların aktif olarak bulundukları piyasaları ve firmaların üretim stratejilerindeki dönemsel değişmeler gözlemlenebilmektedir.

Ancak söz konusu bu ölçüler, ülkelerin, firmaların ve sektörlerin patentleme eğilimlerindeki farklılıklardan etkilenebilir. Dolayısıyla bu etkileri düzeltmek için bazı düzenlemeler yapılması gerekmektedir. Patentleme eğilimindeki ilk fark "ev sahibi ülke" olmaktan kaynaklanmaktadır. Şu bir gerçektir ki, bir buluş veya yenilik ilk önce o buluşun yapıldığ ülkede korunur. Bu yüzden sadece o ülkede alınan patentlerin sayılarına bakmak yanıltıcı sonuçlar doğurabilmektedir. Bir ülkenin vatandaşlarının aldığı patentler, o ülkenin patent enstitüleri ofisinde daha fazla temsil edilirler. Sadece bir ülkenin patent verilerine bakarak, ülkelerin teknolojik güçlerinin belirlenmesi yanıltıcı sonuçlara yol açabilmektedir. Bunu düzeltmenin bir yolu sadece diğer ülkelerde alınan patentlere bakmak olabilir. Diğeri ise; ulusal patent ofislerinden ziyade, Avrupa Patent Ofisi (EPO), Amerika Patent Ofisi veya Japon Patent Ofisi gibi, daha büyük patent ofislerine yapılan yabancı patent başvurularını hesaplamaktır. Ayrıca, iki ülkenin temel patent sayılarının karşılaştırılmasında, referans olarak üçüncü bir piyasa kullanılabilir (Grupp \& Schmoch, 1999: 377): Örneğin iki Avrupa ülkesinin Amerika da ki patentleme faaliyetlerinin karşılaştırılması gibi. 
Ayrıca, ülkelerin temel patent sayıları, bir patent ofisindeki patentlerin toplamının yüzdesi olarak ifade edilebilir ve bu da, ülkelerin patent aktivitelerindeki göreli değişmeleri gösterir. Ülkelerin teknolojik gücünün karşılaştırılmasında, başvuru yapan firmaların pazarlama stratejileri için söz konusu ülkelerdeki enstitülerin güvenilirliği ve uygunluğu önemlidir. Firmalar genellikle üretim veya pazarlama yapabilecekleri ülkelerde koruma talep ederler. Bir firma eğer üretim veya pazarlama yapamayacaksa o ülkede koruma talep etmez. Ancak diğer bir ülkenin firması koruma talep edebilir. Bu durumda, iki ülkenin diğer üçüncü bir ülkedeki patentleme faaliyetlerine bakılarak karşılaştırılması yanıltıcı sonuçlar doğurabilir.

Bununla birlikte, patentlerin bilimsel ve teknolojik faaliyet göstergesi olarak kullanılmasında bazı sınıflama problemleri ortaya çıkabilir. Patent başvurusunda birden fazla mucit, ülke ve sinıflama kodu olabilir. Böyle bir durumda oransal hesabın kullanılması, her bir ülke, mucit veya teknoloji alanı için oransal bir değerin kullanılması daha anlamlı olmaktadır (OECD, 1994: 1-108). Tüm bunlara rağmen, bilimsel ve teknolojik faaliyet göstergesi olarak kullanılan patentler diğer göstergelere kıyasla daha fazla bilgi içeren göstergelerdir.

\section{Patent Verilerinin Sinıflandırılması}

Çalışmanın ikinci bölümünde, patentlerin teknik ve sektörel olarak sınıflandırılması üzerinde durulmuş, teknik bir sınıflama olan ve WIPO' ya üye olan tüm ülkelerde geçerli uluslararası patent sınıflama sistemi (IPC) ile Merit, YTC (Yale Teknoloji Sınıflaması) ve OTC (OECD Teknoloji Sınıflaması) sektörel sınıflama sistemleri irdelenmeye çalışılmıştır.

\subsection{Uluslararası Patent Sinıflandırması (IPC)}

Patent ofislerinin, potansiyel buluş sahiplerinin, araştırma ve geliştirme birimlerinin, teknolojinin gelişimi veya uygulanmasıyla ilgili birimlerin ve diğer kullanıcıların, patent başvurularını yenilik ve buluş basamağı kriterlerine göre değerlendirilebilmesi ve detaylı bir şekilde söz konusu patentlere ait dokümanlara ulaşılabilmesi, ortak bir patent sınıflandırma sistemi kullanımını gerekmektedir. ${ }^{1}$

Patent verilerinin iktisadi anlamda etkilerini bulmaya yönelik çalışmalar için patent verilerinin sınıflandırılması gerekmektedir (Griliches, 1990: 1700). Diğer taraftan, farklı ulusal patent sınıflandırma sistemlerinin kullanımıyla oluşabilecek karışıklığı engellemek için patent dokümanlarının tek ve aynı şekilde sinıflandırılması amaciyla Uluslararası Patent Sinıflandırması (International Patent Classification - IPC) sistemi oluşturulmuştur. ${ }^{2} \mathrm{Bu}$ gereklilik doğrultusunda, IPC Sistemi diğer bir ifade ile uluslararası patent sınıflama sistemi, Strasburg Anlaşması çerçevesinde 1971 yılında yürürlüğe girmiş ve 1979 yılında yenilenmiştir. Türkiye'de de 1 Ekim 1996 y1lında yürürlüğe giren IPC Sistemi dâhilinde, patentlerin, teknolojik alanda, 64000 adet sınıflandırma konusu kapsamında sınıflandırılması kararlaştırılmıştır (TPE, 1996).

Bu sistem sayesinde; teknik ve yasal bilgiye ulaşmayı kolaylaştırmak için, patent dokümanlarının düzgün bir şekilde düzenlenmesi, tüm kullanıcılara patent bilgilerinin teknik alanlara göre sınıflandırılmış bir şekilde sunulması, teknolojinin belli bir alanında tekniğin bilinen durumunun araştırılması ve çeşitli alanlardaki teknolojik gelişmenin değerlendirmesini yapabilmek için sınaî mülkiyet istatistiklerinin hazırlanması mümkün olmaktadır.

IPC sistemi dâhilinde, ilgili patent ofisi tarafindan incelenen ve inceleme sonucunda patent verilmesi kararlaştırılan buluşa ait patent başvuru dosyasına verilen bir IPC kodu ile patent bilgileri sinıflandırılmaktadır. Bu noktada, IPC Sistemi sektörel bir sinıflama olmayıp, sadece, teknik bir sınıflamadır. IPC sisteminde, tüm teknikler, kısımlara, sınıflara, alt sınıflara, gruplara ve alt gruplara ayrılır. Her bir alt grup da alt bir kısıma sahip olabilir. IPC sisteminde bu alt kısımlara harf ve sayıları bir arada

\footnotetext{
${ }^{1}$ http://www.tpe.gov.tr/ipc.htm, 26 Haziran, 2005

2 http://www.tpe.gov.tr/ipc.htm, 26 Haziran, 2005
} 
içeren (alphanumeric) semboller verilir (OECD, 1994: 80). IPC sisteminde, 1 Ocak 2000 tarihinde yapılan yedinci düzenlemeden bu yana, 8 kısım, 21 alt kısım, 120 sınıf, 628 alt sınıf ve yaklaşık 69000 grup vardır. ${ }^{3}$

IPC temel bir ilke olarak yönlendirme işlevine sahiptir. Aynı şekilde, İngiliz ve Amerikan Patent Sistemleri de yönlendirme işlevine sahip sistemlerdir. ${ }^{4}$ Söz konusu bu sistem, şematik olarak, Tablo 1' de gösterilmiştir.

Tabloda da görüleceği üzere, $A, B, C, \ldots$ şeklinde gösterilen her bir kısım (örneğin Kısım G' de cihazlar ve nükleonikler gibi) alt kısımlara ayrılmıştır. Diğer bir taraftan, her bir alt kısım farklı sınıflara (G01, G02, G04, G11, G12, G21 gibi) ve her bir sinıfta farklı alt sinıflara (G01 B, G01 C, ......G01 T...G01 W gibi) ayrılmaktadır. Yine, her bir alt sinıf temel gruplara (A 21 B 1/00, A 21 B 2/00) ve her bir temel grupta alt gruplara (G01 T 3/00, G01 T 3/02, G01 T 3/04, G01 T 3/06, G01 T 3/08 gibi) ayrılmaktadır. Burada görüleceği üzere, her bir kısım, alt kısım, sınıf, alt sınıf, grup ve alt grup bir başlığa ve sembole sahiptir.

Patentlerin ekonomik etkilerinin analiz edebilmesi için patentlerin sektörel bir sınıflamaya tabi tutulmasını gerekmektedir (Griliches, 1990: 1661). Bu noktada sırasıyla, dünyada da geniş bir uygulama alanı bulan, MERIT ve YTC sektörel sınıflama sistemleri üzerinde durulacaktır.

\subsection{MERIT Sinıflaması}

MERIT sınıflamasını ilk kez yapanlar Verspagen, Moergastel ve Slabber ( 1994) olmuştur. MERIT sınıflaması IPC kodlarını 4- hane ( digit) düzeyinde ISIC' a çevirmektedir. MERIT sınıflama sisteminde, ISIC kategorisi ile ilgili 4- hane düzeyindeki her bir IPC sınıfına belirli bir yüzdelik verilir. Örneğin; IPC kodu A45D olan patenttin \% 40'1 ISIC kodu 3830 (3832 hariç) olan elektrik makineleri sanayisinde, geri kalan \% 60'lık kısmı da ISIC kodu 3900 olan diğer endüstri ürünlerin de sınıflandırılır. Aynı şekilde, örneğin; IPC kodu CO7K olan patentin tamamı diğer bir ifade ile \% 100' ü ISIC kodu 3522 olan ilaç sanayisinde sınıflandırılır. MERIT sınıflama sistemi, imalat sanayi için 22 sektörü ISICs içerisinde gruplar. MERIT sınıflamasında, sektör kodlarının ISIC REV. 2' deki karşılıkları Tablo 2' de verilmiştir.

\subsection{Yale Teknoloji Sınıflaması (YTC)}

Genel anlamda bakıldığında IPC sistemi, esasen patente konu olan teknolojik yeniliğin gruplandırılmasından öte bir şey olmamakla birlikte aynı IPC kodu altında gruplandırılan her bir patente konu olan teknolojik yenilik, sektörel anlamda homojen olmamaktadır. Kaldı ki söz konusu teknolojik yenilik ortaya konulduğu ve kullanıldığı sektörler açısından da farklılıklar gösterebilmektedir. Dolayısıyla böylesine karmaşık ilişkiler ağından oluşan teknolojik yeniliklerin tek başına sektörel tasnifinin bile anlamlı olamayacağı, söz konusu teknolojik yeniliklere ilişkin patentlerin kullanıldığı ve yaratıldığı sektörler açısından da sınıflandırılmasının kaçınılmaz olacağını söylemek mümkündür.

Bu noktada YTC sitemine bakıldığında IPC kodlarını IOM (patentlerin üretildiği sektörler) ve SOU' ya (patentlerin kullanıldığı sektörler) göre sınıflandırdığı görülmektedir ve bu bağlamda son derece önemli bir sorunu da ortadan kaldırmaktadır. YTC sistemi, 1976- 1993 yıllarında Kanada da tescil edilmiş 250000 den fazla patent kullanılarak oluşturulmuştur. Kanada Patent Ofisi her patenti IPC kodlarına ve IOM, SOU' a göre ayırmaktadır. YTC' nin orijinal anlamda ilk kurucuları Kortum, Putnam ve Evenson dur. Daha sonra, Johnson (2005) YTC'yi, 1995 yılını da dâhil ederek, 300000 fazla patent sayısıyla genişletip bir olasılık matrisi formuna sokarak yeniden güncelleştirmiş ve IPC kodlarını IOM ve SOU'ya çevirerek patentlerin, girdi-çıktı tablolarını oluşturmuştur. YTC sisteminde 42 tane IOM ve 50 tanede SOU vardır. ${ }^{5}$ Kortum ve Putnam (1997: 261)’ e göre, YTC birçok ülkede rahatlıkla uygulanabilir bir sistemdir.

\footnotetext{
${ }^{3}$ http://www.wipo.int/treaties/classification/strasbourg/index.html, 27 Haziran, 2005.

${ }_{5}^{4}$ http://www.wipo.int/treaties/classification/strasbourg/index.html, 27 Haziran, 2005.

5 Johnson-Evenson Patent Set, www.wellesley.edu/Economics/johnson/jeps/index.htm, 29 Haziran, 2005
} 
Keller (1997: s. 213) toplam faktör verimliliği analizinde YTC'yi kullanarak oluşturulan sektörler arasındaki A\&G verileri ile yine YTC'yi kullanarak oluşturulan girdi- çıktı verileri arasında pozitif ve anlamlı bir ilişki bulmuştur. Fikkert (1997: 193) YTC sınıflamasının bazı ampirik hatalara yol açabileceğini, ancak, bu durumun YTC'nin olumlu özelliklerini göz ardı etmemizi gerektirmeyeceğini vurgulamış, YTC sisteminin farklı ülkeler ve farklı endüstriler için uygulandığında bu tür sorunların ortaya çıkabileceğini ifade etmiştir.

Kortum ve Putnam (1997: 261) Kanada Patent Ofisinin (CIPO) Kanada patentleri için yapmış olduğu endüstri tayininin, diğer bir ifade ile YTC sisteminin güvenilirliliğini test etmişlerdir. Bunun için 1983 yılı ile 1993 yılları arasında Kanada'da tescil edilen patentleri kullanmışlardır. Patentlerin endüstri tayini yapılırken, söz konusu patentlere ait başvuru dosyalarında belirtilen teknoloji alanının ve/veya alanlarının, söz konusu patentlerin hangi endüstriye ve/veya endüstrilere tayin edileceğini belirlemede önemli bir rol üstlendiğini ifade etmişlerdir. Her bir ülke ve Kanada'da tescil edilen Amerikan patentleri için YTC sisteminin güvenilirliğini test etmişlerdir. Yapılan tahminler sonucunda, model içerisinde, YTC sistemi dâhilinde endüstri tayini yapılmış olan patentlere ait katsayıların standart hatalarının küçük olduğunu bulmuşlardır.

\subsection{OECD Teknoloji Sınıflaması (OTC)}

OECD teknoloji sınıflaması diğer bir ifadeyle OTC sistemi işlerlik açısından temelde YTC sistemine dayanmaktadır ve YTC sistemi ile arasında benzerlikler vardır. Bu benzerliklerin başında her bir IPC kodlu patent dosyalarını YTC'deki gibi IOM (patentlerin üretildiği sektörler) ve SOU'ya (patentlerin kullanıldığg sektörler) göre sınıflandırması gelmektedir. İkinci olarak IPC kodlarının sektör sınıflamasını yaparken YTC sistemindeki gibi her bir IPC kodunu SIC sektörlerine ayrıştırmaktadır. Ancak YTC sisteminden farklı olarak OTC sistemi aynı zamanda SIC sektörlerinin ISIC dönüşümlerini de sunmaktadır (Johnson, 2002).

OTC sisteminde YTC sisteminden farklı olarak 126 tane SOU (kullanıcı sektör), 66 tanede IOM (üretici sektör) vardır. Johnson (2002: 1) yapmış olduğu çalışmada rastgele örneklem yoluyla seçilmiş olan 400 adet ABD patentinin ve 1500 adet EPO patentinin OTC sınıflaması sonucunda elde etmiş olduğu IOM ve SOU değerlerinin güvenilirliğini test etmiş ve sonuç olarak gerek ABD gerekse EPO için yüksek korelasyonlu benzer sonuçlara ulaşmıştır. Sonuç olarak Johnson (2002: 1) OTC sisteminin patent veri analizi açısından son derece faydalı bir araç olduğunu vurgulamaktadır.

\subsection{MERIT, YTC ve OTC Sistemlerinin Karşılaştırılması}

IPC kodlarının sektörel olarak sınıflandırılmasında, YTC ve MERIT sınıflandırma sistemleri arasında bazı farklılıklar vardır. İlk olarak; YTC sınıflama sistemi, patentlerin IPC kodlarını 7- hane düzeyine kadar dikkate alırken; MERIT sınıflandırma sistemi patentlerin IPC kodlarını 4- hane düzeyine kadar dikkate almaktadır. YTC ve OTC sistemleri IPC kodlarını 4- hane düzeyindeki SIC sektörlerine ayrıştırırken; MERIT sistemi IPC kodlarını 4- hane düzeyindeki ISIC sektörlerine ayrıştırmaktadır. Diğer bir ifade ile tek bir patente ait IPC kodu YTC sinıflama sisteminde 7- hane düzeyinde, örneğin C07D 201 olarak sinıflandırılırken, aynı patentin MERIT sistemindeki IPC kodu 4- hane düzeyinde C07D olarak sınıflandırılmaktadır. Diğer bir farklılıksa; YTC ve OTC sistemi MERIT sisteminden farklı olarak her bir IPC kodunu ikili bir ayrıma tutar. Diğer bir ifade ile YTC ve OTC sistemi her bir IPC kodunu üreten ve kullanan sektörlere göre ayrıştırır. Fakat MERIT' de böyle bir ayrıştırma söz konusu değildir. YTC sisteminde 50 tane kullanıcı sektör, 42 tanede üretici sektör vardır. MERIT sisteminde ise IPC kodları imalat sanayi içerisinde 22 alt sektöre ayrıştırılır (OECD, 1994: 10). OTC sisteminde ise 126 tane kullanıcı sektör, 66 tanede üretici sektör vardır. 


\section{Sonuç}

Son yillarda küreselleşme süreci ile birlikte, fiyat merkezli rekabet stratejileri yerini teknolojik yenilik (inovasyon) merkezli rekabet stratejilerine bırakmıştır. Dolayısıyla teknolojik yenilik ortaya koyabilmenin en önemli unsurlarını oluşturan; bilimsel ve teknolojik faaliyetlerin en önemli girdisini oluşturan $A \& G$ faaliyetlerinin ve $A \& G$ faaliyetlerinin somut bir ürünü olan patentlerin önemi artmıştır.

Bilim ve teknoloji faaliyetleri, bir ülkenin teknoloji kapasitesinin ve ekonomik kalkınmasının seyrini belirler. Dolayısıyla; bilim ve teknoloji faaliyetleri ile ekonomik değişkenler arasındaki ilişkinin anlaşılabilmesi ve iktisadi anlamda bu ilişkinin modellendirilebilmesi için, bilimsel ve teknolojik faaliyetleri temsil edebilecek göstergelerin bulunması gerekmektedir. Ancak bilimsel ve teknolojik faaliyetleri tam anlamıyla temsil edebilecek bir gösterge yoktur. İktisadi çalışmalarda en çok kullanılan göstergeler A\&G faaliyetleri ile patent verileridir. Bu noktada her iki göstergenin de avantajları ve dezavantajları vardır. Patent verileri teknolojik değişmenin önemli bir göstergesi ve aynı zamanda A\&G faaliyetlerinin de bir çıktısıdır. Patent verileri ile A\&G faaliyetleri tam olarak örtüşmese de, aralarında güçlü ve pozitif bir ilişki vardır. $B u$ yüzden, $A \& G$ faaliyetleri ile ilgili sağlıklı veriler bulunamadığında, patent verileri, $A \& G$ faaliyetleri yerine kullanılabilmektedir.

Patent verilerinin bilimsel ve teknolojik faaliyetlerin bir göstergesi olarak kullanımında ise bazı dezavantajlar vardır. İlk olarak; buluşların sınıflandırılmasında patentlere konu olan buluşların önem itibariyle birbirinden farklı olmaları nedeniyle birtakım sorunlar ortaya çıkabilmektedir. Diğer bir sorun da patent enstitülerinde çalışan uzmanlardan kaynaklanmaktadır. Yetkin bir uzman patentleri doğru grupta sinıflandırırken, görece yetersiz bir uzman patentleri farklı bir grupta sinıflandırabilir ve bu durum patentlerin ekonomik analizlerinde yanlış sonuçlara ulaşılmasına neden olabilir. Diğer bir sorun ise patentlere konu olan buluşların etkilerinin önemi açısından farklı olmasıyla ilgilidir. Bazı buluşlar insanlık tarihinde çığır açarken, bazıları çok önemsiz kalabilir. Bu önem farklılıkları ne yazık ki patent verilerinden anlaşılamaz ve böyle bir önem sıralaması yapılamaz.

Patentler ile ilgili diğer bir sorun da tüm buluşların patentlenmemesi veya patentlenememesinden kaynaklanmaktadır. Bazı durumlarda buluş sahibi, buluşunu korumak için patent yerine gizlilik ve/veya düşük fiyat gibi başka yöntemlere başvurabilmektedir. Diğer taraftan, bilimsel teoriler, matematiksel modeller, bitki ve hayvan çeşitleri ile ticari metotlara yasal olarak patent hakkı verilemez.

Patentlere konu olan buluşlar hem kalite hem de yarattıkları katma değer açısından birbirinden farklıdırlar. Dolayısıyla, bu farklılıklar buluşları birbirinden ayırmamızı ve buluşların ekonomik etkilerini anlamamızı engellemektedir. Her ne kadar patent verilerinin kullanımında bazı dezavantajlar olsa ve bu dezavantajlar gelişmekte olan ülkelerde daha da belirgin olarak ortaya çıssa da patent verileri bilimsel ve teknolojik faaliyetlerin en önemli göstergelerinden birisidir.

İlk olarak; patent verileri, A\&G çıktısı ile buluş ve inovasyon aktiviteleri için iyi bir göstergedir ve bir ülke veya sektörün teknoloji düzeyi hakkında detaylı ve yeterli bilgiye sahip olunamadığı durumlarda, patentler bu bilgileri sağlamaktadır. İkinci olarak; patent verileri, dünya genelinde, patent ofisleri tarafından bilgisayar ortamında belirli bir sistematik içerisinde toplandığı için; firma, sektör veya ülke düzeyinde teknolojik gelişmenin seyrinin analiz edilmesine olanak sağlar. Çünkü bu veriler bir zaman serisi olarak detaylı bir şekilde sunulmaktadırlar. Dolayısıyla; patent verileri aracılığı ile ülkelerin buluş çıktı düzeyi ve rekabet kapasiteleri arasındaki ilişkinin analiz edilmesi mümkün olmaktadır. Özetle; detaylı bilgiler içeren patent dosyaları, bir ülkenin, firmanın veya sektörün teknolojik gücünü değerlendirebilmemizi, karşılıklı ülkelerin patentleme faaliyetlerini ve rekabet güçlerini analiz edebilmemizi, söz konusu ülkelerin sektörel uzmanlaşmasını ve teknolojik ürün dönemlerini araştırabilmemizi mümkün kılmaktadır.

Patentler; buluş sahibine söz konusu bulusun üretiminde, ticaretinde ve her türlü tasarrufunda, belirli bir süre dâhilinde, tekel hakkı sağlayan yasal bir belgedir. Diğer taraftan, fikri ve sınaî mülkiyet haklarını oluşturan en önemli unsurlardan da birisidir. Bu noktada, patent hakları; buluşları teşvik etmesi, yeniliklerin ticarete konu olmasını sağlaması, buluşların yayılmasına yardımcı olması gibi faydaları ile gerek teknolojik 
faaliyetlerin genişlemesi ve yayılması üzerinde, gerekse ticaretin performansı üzerinde ve dolayısıyla ekonomik büyüme üzerinde çok önemli etkilere sahiptir.

Günümüz dünyasında bilgiye dayalı faaliyetlerin artması, küresel alanda ekonomik faaliyetlerin ve uluslararası ticaretin gelişmesi nedeniyle, fikri ve sınaî mülkiyet haklarının korunmasına yönelik talepler de artmıştır. Dolayısıyla, fikri ve sınaî mülkiyet haklarının en önemli unsurlarından biri olan patent haklarının giderek önem kazanması, patent haklarının dünya genelinde, uluslararası sözleşmeler aracılığı ile standartlaştırılmasını da gerekli kılmıştır.

Bu bağlamda, bir buluşun ve/veya yeniliğin patent hakkına sahip olabilmesi için, söz konusu bulusun sanayiye uygulanabilir olması, yenilik içermesi ve buluş niteliği taşıması gibi dünya genelinde standartlaştırılmış özelliklere sahip olması gerekmektedir. Farklı ulusal patent sınıflandırma sistemlerinin kullanımıyla oluşabilecek karışıklığı engellemek için patentlerin uluslararası alanda aynı şekilde sınıflandırılmasını sağlayan Uluslararası Patent Sınıflandırma Sistemi (International Patent ClassificationIPC) oluşturulmuştur. IPC sistemi sektörel bir sınıflama sistemi olmayıp, sadece teknik bir sınıflamadır ve patente ait buluşun hangi teknolojik alana ait olduğunun tespitini sağlamaktadır.

Ancak, ekonomik bir analiz yapabilmek için patentlerin sadece IPC sınıflamasının yapılması yeterli olmayıp, aynı zamanda sanayi sınıflandırmasına göre de sınıflandırılmaları gerekmektedir. Dünyada bizim bildiğimiz kadarıyla bunu yapan dört farklı sinıflandırma sistemi vardır. Bunlardan ilki OTAF (The Office of Technology Assessment and Forecast) olarak bilinen ve sadece A.B.D.'de kullanılan sistemdir. Diğeri, YTC (Yale Technology Concordance) olarak bilinen ve patent sinıflandırmalarını Standart Sanayi Sinıflandırmasina (Standard Industrial Classification) uyumlu hale getiren sistemdir. YTC bu uyumlaştırmayı yaparken patentleri üretildikleri sektörlere (YTC-IOM) ve kullanıldıkları sektörlere göre (YTC-SOU) iki farklı gruba ayırır. Diğer bir sanayi sınıflama sistemi MERIT'in (Maastricht Economic Research Institute on Innovation and Technology) yaptığı ve patentleri Uluslararası Standart Sanayi Sınıflandırmasına (International Standard Industrial Classification) uyumlu hale getiren sistemdir. Diğer bir sınıflama sistemi ise OECD teknoloji sınıflaması diğer bir ifadeyle OTC sistemi olarak bilinen sınıflama sistemidir. OTC işlerlik açısından temelde YTC sistemine dayanmaktadır ve YTC sistemi ile arasında benzerlikler vardır. Ancak, YTC sisteminden farklı olarak OTC sistemi aynı zamanda SIC sektörlerinin ISIC dönüşümlerini de sunmaktadır. 


\section{KAYNAKÇA}

ALBUQUERQUE, E. (2000), "Domestic Patents and Developing Countries: Arguments for Their Study and Data from Brazil (1980-1995)", Research Policy, 29, s. 1047-1060.

ARCHIBUGİ, D. ve Michie, J. (1995), "The Globalization of Technology: A New Taxonomy", Cambridge Journal of Economics, 19, s. 121-140.

CANTWELL, J. (1995), "The Globalization of Technology: What Remains of the Product Cycle Model?", Cambridge Journal of Economics, 19, s. 155-174.

EUROPEAN INNOVATION MONITORING SYSTEM (EIMS) (1996), "Innovation Outputs in European Industry: Analysis from the C.I.S.”, EIMS Publication, European Commission, No 34.

FIKKERT, B. (1997), "Application of the Yale Technology Concordance to the Construction of International Spillover Variables for India", Economic System Research, 9, 2, s. 193-204.

GRILICHES, Z. (1990), "Patent Statistics as Economic Indicators: A survey", Journal of Economic Literature, XXVIII, s. 1661-1707.

GRUPP, H. ve SCHMOCH, U. (1999), "Patent Statistics in the Age of Globalization: New Legal Procedures, New Analytical Methods, New Economic Interpretation”, Research Policy, 28, s. 377-396.

GUERRERO, D., C. ve SERO, M., A. (1997), "Spatial Distribution of Patents in Spain: Determining Factors and Consequences on Regional Development", Regional Studies, 31, 4, s. 381-390.

http://www.tpe.gov.tr/ipc.htm, (Erişim Tarihi:26.06.2010).

http://www.tpe.gov.tr/ipc.htm, (Erişim Tarihi:26.06.2010).

http://www.wipo.int/treaties/classification/strasbourg/index.html, (Erişim Tarihi:27.06.2010).

http://www.wipo.int/treaties/classification/strasbourg/index.html, (Erişim Tarihi:27.06.2010).

JOHNSON, D. ve EVENSON, R. (1997), "Innovation and Invention in Canada", Economic Systems Research, 9, 2, s. 177-192.

JOHNSON, D. K. (2002), "The OECD Technology Concordance (OTC) Patents by Industry of Manufacture and Sector of Use", OECD Science, Technology and Industry Working Papers, 2002/5, s. 1-40.

JOHNSON, D. K. ve Evenson, R. (2005), "Johnson-Evenson Patent Set", http://www.welleley.edu/Economics/johnson/jeps/index.htm, (Erişim Tarihi:22.06.2005).

KELLER, W. (1997), “Technology Flows between Industries: Identification and Productivity Effects", Economic Systems Research, 9, 2, s. 213-220.

KORTUM, S. ve PUTNAM, J. (1997), "Assigning Patents to Industries: Tests of the Yale Technology Concordance", Economic Systems Research, 9, 2, s. 261-275.

MANCUSİ, M. (2000), "The Dynamics of Technology in Industrial Countries", CESPRI Working Paper, No. 118, Universita Commerciale "Luigi Bocconi" Milan Italy, s. 1-28. 
MAZZOLENI, R. ve Nelson, R. R., (1998), "The Benefits and Costs of Strong Patent Protection: A Contribution to the Current Debate", Research Policy, 27, s. 273-284.

OECD, (1980), Bilimsel ve Teknik Çalısmaların Ölçülmesi: Frascatı El Kitabı, 1. Baskı, Değişim Yayınları, Ankara, s. 2-20.

OECD, (1994), The Measurement of Scientific and Technological Activities: Using Patent Data as Science and Technology Indicators Patent Manual 1994, OECD/GD, 94, 114, Paris, s.1-108.

PATEL, P. ve PAVITT, K. (1995), Divergence in Technological Development among Countries and Firms: J. Hogedoorn (ed.), Technical Change and the World Economy içerisinde, Edward Elgar, England, s. 147182.

PATEL, P. (1995), "Localised Production of Technology for Global Markets", Cambridge Journal of Economics, 19, s. 141-153.

SCHMOOKLER, J. (1966), Invention and Economic Growth, Harvard University Press, Cambridge, Massachusetts.

TPE (1996), 100 Soru Cevap, Yayın No.: TPE/7, MKE Vakfı Matbaası, Ankara.

UNESCO (1978), Recommendation Concerning the International Standardization of Statistics on Science and Technology, Paris, s. 1-202.

VERSPAGEN, B., MOERGASTEL, T. V. ve SLABBERS, M. (1994), "MERIT Research Memorandum 2/94-004", http://www.merit.unimaas.nl/publications/rmpdf/1994/rm94_004.pdf.,

(Erişim

Tarihi:26.06.2005). 
Ek:

Tablo 1: IPC Sistem Şeması

KISIM A- İnsan İhtiyaçları

KISIM B- Operasyonları Uygulama; Nakletme (Taşıma)

KISIM C- Kimya; Metalürji

KISIM D- Tekstil, Kâğıt

KISIM E- İnşaat

KISIM F- Mekanik Mühendisliği; Aydınlatma; Isıtma; Silahlar; Tahrip malzemeleri

KISIM G- Fizik

- Cihazlar

G 01- Ölçme test etme

G 01 B- Uzunluk, kalınlık ya da benzer doğrusal boyutların ölçülmesi;

G 01 C- Navigasyon ya da muayene için uzaklıkların, seviyelerin ve sapmaların ölçülmesi, jiroskobik aletler, fotogrametri

G 01 T- Nükleer ya da X-radyasyonunun ölçülmesi

G $01 \mathrm{~T}$ 1/00 X- radyasyonu, gamma radyasyonu, parçacık radyasyonu ya da kozmik radyasyonun ölçülmesi

G 01 T 3/00 Nötron radyasyonunun ölçülmesi

G 01 T 5/00 Parçacık hareketlerinin ya da izlerinin kaydedilmesi, bu tip izlerin işlenmesi ya da analizi

G 01 T 7/00 Radyasyon ölçüm cihazlarının detayları

G 01 V- Jeofizik, yer çekimsel ölçümler, kütlelerin ya da objelerin tetkik edilmesi, taglar

G 01 W- Meteoroloji

G 02- Optik

G 04- Horoloji- vakit ölçme birimi

G 11- Bilgi depolama

G 12- Alet detayları

- Nükleonikler

G 21- Nükleer fizik; nükleer mühendisliği

KISIM H- Elektrik

Kaynak: WIPO 